\title{
1,635 Endoscopic submucosal dissection cases in the esophagus, stomach, and colorectum: complication rates and long-term outcomes
}

\author{
Takashi Toyonaga $\cdot$ Mariko Man-i $\cdot$ James E. East $\cdot$ Eisei Nishino $\cdot$ Wataru Ono • \\ Tomoomi Hirooka • Chie Ueda • Yoshinori Iwata • Takeshi Sugiyama • Toshio Dozaiku • \\ Takashi Hirooka · Tsuyoshi Fujita $\cdot$ Hideto Inokuchi $\cdot$ Takeshi Azuma
}

Received: 22 June 2012/Accepted: 21 August 2012/Published online: 6 October 2012

(C) The Author(s) 2012. This article is published with open access at Springerlink.com

\begin{abstract}
Background Endoscopic submucosal dissection (ESD) enables en bloc resection of early gastrointestinal neoplasms; however, most ESD articles report small series, with short-term outcomes performed by multiple operators on single organ. We assessed short- and long-term treatment outcomes following ESD for early neoplasms throughout the gastrointestinal tract.

Methods We performed a longitudinal cohort study in single tertiary care referral center. A total of 1,635 early gastrointestinal neoplasms (stomach 1,136; esophagus 138; colorectum 361) were treated by ESD by single operator. Outcomes were complication rates, en bloc R0 resection rates, and long-term overall and disease-specific survival
\end{abstract}

This data was presented as a presidential plenary oral presentation at DDW 2009, June 3, Chicago: Man-i M, Toyonaga T, Azuma T, et al. Long-term results of endoscopic submucosal dissection for earlystage gastrointestinal tumors. Gastrointest Endosc 2009;69:AB133.

Clinical Trials Registry (UMIN-CTR) Number UMIN000006140.

T. Toyonaga ( $\square)$

Department of Endoscopy, Kobe University Hospital,

7-5-1 Kusunoki-cho, Chuo-ku, Kobe, Hyogo 650-0017, Japan

e-mail: toyonaga@med.kobe-u.ac.jp

M. Man-i · T. Fujita · T. Azuma

Frontier Medical Science in Gastroenterology, Kobe University

School of Medicine, Kobe, Hyogo, Japan

J. E. East

Translational Gastroenterology Unit, John Radcliffe Hospital,

Oxford, United Kingdom

E. Nishino

Pathology, Kishiwada Tokushukai Hospital, Kishiwada,

Osaka, Japan rates at 3 and 5 years for both guideline and expanded criteria for ESD.

Results En bloc R0 resection rates were: stomach: 97.1\%; esophagus: $95.7 \%$; colorectum: $98.3 \%$. Postoperative bleeding and perforation rates respectively were: stomach: 3.6 and $1.8 \%$; esophagus: 0 and $0 \%$; colorectum: 1.7 and $1.9 \%$. Intra criteria resection rates were: stomach: $84.9 \%$; esophagus: $81.2 \%$; colorectum: $88.6 \%$. Three-year survival rates for lesions meeting Japanese ESD guideline/expanded criteria were for all organ-combined: 93.4/92.7 \% . Five-year rates were: stomach: 88.1/84.6\%; esophagus: $81.6 / 57.3 \%$; colorectum: $94.3 / 100 \%$. Median follow-up period was 53.4 (range, 0.07-98.6) months. Follow-up rate was $94 \%(1,020 / 1,085)$. There was no recurrence or disease-related death.

Conclusions In this large series by single operator, ESD was associated with high curative resection rates and low complication rates across the gastrointestinal tract. Disease-specific and overall long-term prognosis for patients with lesions within intra criteria after curative resection appeared to be excellent.

W. Ono $\cdot$ C. Ueda

Gastroenterology, Kishiwada Tokushukai Hospital,

Kishiwada, Osaka, Japan

T. Hirooka $\cdot$ T. Dozaiku $\cdot$ T. Hirooka

Gastroenterology, Fuchu Hospital, Izumi, Osaka, Japan

Y. Iwata

Gastroenterology and Hepatology, Hyogo College of Medicine,

Nishinomiya, Hyogo, Japan

T. Sugiyama

Gastroenterology, Sakibana Hospital, Izumi, Osaka, Japan

H. Inokuchi

Gastroenterology, Hyogo Cancer Center, Akashi, Hyogo, Japan 
Keywords Endoscopic submucosal dissection . Complication $\cdot$ Postoperative $\cdot$ Prognosis $\cdot$ Neoplasms

$\begin{array}{ll}\text { Acronyms } & \\ \text { ESD } & \text { Endoscopic submucosal dissection } \\ \text { EMR } & \text { Endoscopic mucosal resection } \\ \text { UMIN-CTR } & \text { University Hospital Medical Information } \\ & \text { Network-Clinical Trials Registry } \\ \text { ade } & \text { Adenoma } \\ \mathrm{m} & \text { Mucosal } \\ \mathrm{sm} & \text { Submucosal } \\ \mathrm{ca} & \text { Cancer } \\ \mathrm{diff} & \text { Differentiated } \\ \text { ly } & \text { Lymphatic invasion } \\ \mathrm{v} & \text { Vascular invasion } \\ \text { UL } & \text { Ulceration } \\ \text { LGIN } & \text { Low grade intraepithelial dysplasia } \\ \text { HGIN } & \text { High grade intraepithelial dysplasia } \\ \text { EP } & \text { Epithelium } \\ \text { LPM } & \text { Lamina propria mucosae } \\ \text { MM } & \text { Muscularis mucosa } \\ \text { inf } \alpha & \text { Infiltrative growth pattern, expansive type } \\ \text { CI } & \text { Confidence interval }\end{array}$

Early gastrointestinal tract neoplasia is increasingly recognized and detected by endoscopists, due to improvements in endoscopic image quality and increased education and awareness of these often flat lesions [1]. It is now accepted that even large lesions can be endoscopically curatively managed as long as they are not deeply invasive. Endoscopic mucosal resection (EMR) with or without a cap has been the primary technique for managing these lesion; however, EMR of lesions larger than $20 \mathrm{~mm}$ in diameter often results in piecemeal resection, which may lead to inconclusive or incorrect histopathological evaluation and local recurrence.

Endoscopic submucosal dissection has enabled en bloc resection of lesions that are difficult to remove en bloc by conventional endoscopic mucosal resection (EMR) [2-9] regardless of tumor location and size. ESD was introduced for treatment of larger mucosal cancers and slightly invasive submucosal cancers in the upper and lower gastrointestinal tract, which have a very low incidence of lymph node metastasis, making them potentially candidates for endoscopic treatment $[10,11]$. ESD is the procedure of choice for early gastric cancer in Japan and is increasingly used for esophageal and colorectal lesions. Experience is growing in the rest of Asia, Europe, and Latin America, but use in the United States is very rare.

Many articles have reported the treatment results of ESD; however, most of them were relatively small series and often were performed by multiple operators. This makes it difficult to assess precisely aspects such as complication and en bloc resection rates, because adverse events are relatively rare and may vary substantially between operators and organs. Importantly, there are few reports about the long-term outcomes of ESD in terms of recurrence rates and survival with an acceptable large dataset and follow-up period.

In this retrospective longitudinal cohort study, we assessed short-term and long-term treatment outcomes for a large number ESDs for early gastrointestinal neoplasms in the esophagus, stomach, and colorectum by single operator. We particularly focus on long-term survival both overall and by organ.

\section{Patients and methods}

A total of 1,659 lesions (stomach 1,145; esophagus 139; colorectum 375) were attempted for ESD, and 1,635 lesions/1,261 patients (stomach 1,136/821; esophagus 138/111; colorectum 361/329) were completed between May 2002 and July 2007 and were analyzed retrospectively. Cases with multiple lesions were included, and patients with recurrence after EMR were included in this study. The study protocol was approved by the Ethics Committee of Kishiwada Tokushukai Hospital. This study has been registered in the University Hospital Medical Information Network Clinical Trials Registry (UMIN-CTR) as number UMIN000006140. The process of treatment, including complications and the possibility of additional surgery because of perforation or the pathologic diagnosis of resected specimens, was clearly explained to all patients, and their written informed consent was obtained. All noncompleted cases underwent surgical treatment.

\section{Criteria}

The criteria for ESD were determined by the endoscopic characteristics and histological findings of biopsy specimens; endoscopic ultrasonography also was performed when the lesion was strongly suspected of submucosal invasion. The criteria in this report were shown in Box 1 , which broadly follow Japanese guidelines.

\section{Method of ESD procedure}

All procedures were performed by one experienced endoscopist (TT) who had conducted more than 2,000 ESDs during a period of 5 years. The outline of the procedure is described hereunder. 
Box 1 Criteria in this study

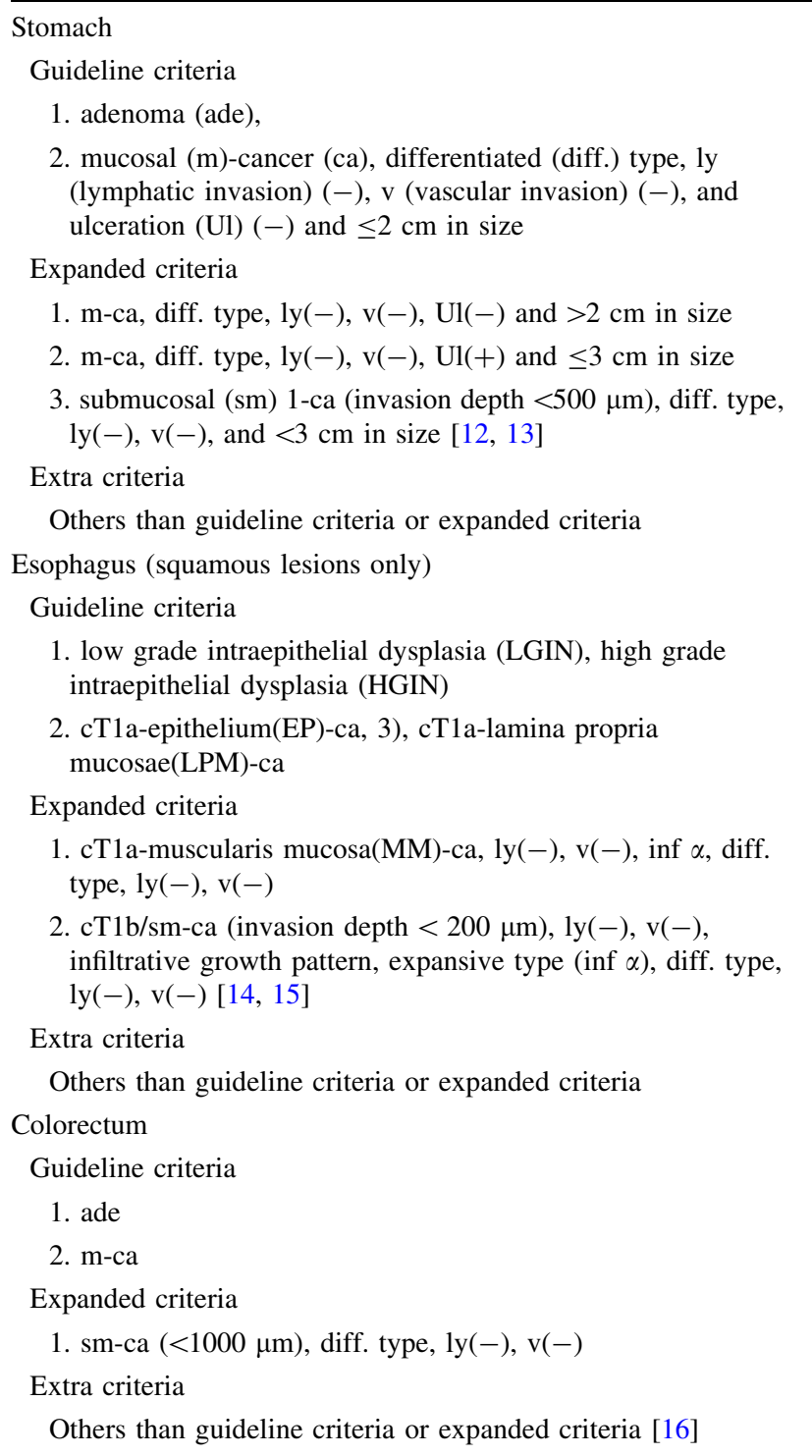

Technical devices

\section{Primary endo-knives}

We used the FlexKnife (KD-630L, Olympus Optical Co, Ltd, Tokyo, Japan) [5, 8] in the colorectum and short needle knife in the esophagus between May 2002 and June 2005, FlushKnife (DK-2618JN, Fujifilm Optical Co, Ltd, Tokyo, Japan) [17, 18] following June 2005, and IT knife (KD-610L, Olympus) [2, 3] mainly in the stomach and not in the colorectum. FlushKnife is a short needle knife with water jet emitting function, which can dissect severe fibrosis and also add the local injection by knife itself.
Ancillary devices

The conventional Needle knife (KD-10Q-1, Olympus), precut Needle knife, the Hook knife (KD-620LR, Olympus) [4], and ST hood (DH-16CR, Fujinon) were used as ancillary devices.

\section{Endoscopes}

A single channel endoscope (GIF Q 240I for esophagus and stomach, Olympus; CF 240I for colorectum, Olympus) was used with a $4 \mathrm{~mm}$-long, transparent hood to keep a clear operating field.

\section{Electrosurgical generator}

ICC200, VIO 300D (ERBE Elektromedizin GmbH, Tubingen, Germany) was used as the electrosurgical generator.

\section{Injection solution}

Saline for the stomach and diluted sodium hyaluronate solution (MucoUp; Johnson \& Johnson K.K., Tokyo, Japan) for the esophagus and colorectum was used as local injection into the submucosal layer providing a distinct and long-lasting mucosal elevation [19].

\section{ESD technique}

The lesions were first identified and demarcated using white-light endoscopy, magnifying endoscopy, and chromoendoscopy. Then, marking around the lesions was performed except in the colorectum. Local injection was made using injection needle, and then mucosal incision was performed around the lesion using primary endo-knives. Additional local injection was made using injection needle or Flush knife. Submucosal dissection was performed using primary endo-knives; however, ancillary devices were used combined in difficult cases. Hemostasis and vessel coagulation were practiced using primary endo-knives or hemostatic forceps. The precise procedure has been described elsewhere [17, 18, 20-23].

\section{Postoperative bleeding}

Postoperative bleeding was defined as the decrease of hemoglobin by $2 \mathrm{~g} / \mathrm{dl}$ caused by hematemesis or melena and the need for hemostatic treatment by endoscopic management. 


\section{Perforation}

Immediate perforation was recognized endoscopically and was treated by endoscopic clipping, fasting, and antibiotics. Clinical examination and an erect chest and abdominal x-ray were performed routinely 1 day postprocedure to look for delayed perforation. Delayed perforation was treated by surgical intervention for fear of severe peritonitis caused by enteric bacteria, when the inflammation manifested as localized abdominal pain, leucocytosis, and occasionally fever were uncontrollable by conservative treatment.

\section{Histopathological assessment}

The resected specimens were stretched and fixed onto a rubber plate and immersed in formalin and sectioned serially at $2 \mathrm{~mm}$ intervals and subjected to histopathological examination.

En bloc resection, en blocR0 resection, intra-criteria resection

Resection of the lesion in a single piece was defined as en bloc resection. Resection of lesions in one piece with margins free of the tumor was defined as en bloc R0 resection. The minimum distance required for margin free was $0.5 \mathrm{~mm}$ in lateral side and $50 \mu \mathrm{m}$ in vertical side.

Specimens meeting the above guideline criteria or expanded criteria were considered to represent curative resection with little risk of lymph node metastasis, and described as intra-criteria resection (Box 1), with guideline and expanded criteria.

\section{Follow-up}

Those cases in which after resection, pathology indicated that they continued to be within guideline or expanded criteria for ESD following pathological examination (intracriteria cases) were examined by periodic surveillance endoscopy to check for recurrence (stomach and esophagus: generally 6 months after ESD, and every 1 year thereafter; colorectum: generally 1 year after ESD, and every 3 years thereafter). We routinely performed systematic chromoendoscopy of the scar site. Biopsy was performed in any case where recurrence was suspected. The cases also are examined by annual thoracic and abdominal computed tomography. The data were collected from the medical records. Incomplete data were investigated from the telephone contact with patients, family, or a request for information from the referring physician.

Patients whose lesions were found to be outside the guideline or expanded criteria for ESD following pathological examination (extra criteria cases) were advised to undergo further surgery. The cases surveyed until June 2009 were defined as the cohort who underwent follow-up, and the flow diagram of patient's follow-up is shown in Table 1.

Evaluated parameters

The retrospectively evaluated data included the en block resection rate, en bloc $\mathrm{R} 0$ resection rate, rates of cases under the guideline criteria and expanded criteria, intra-criteria resection rate, tumor diameter, resected specimen diameter, macroscopic type, location, postoperative bleeding rate, and perforation rate. All procedures were recorded on videotape and parameter, such as perforation was noted for evaluation. Data are reported according to the STROBE guidelines for reporting observational studies [24].

\section{Statistics}

Values were presented as medians. Independent continuous variables were compared by the Mann-Whitney test, and categorical variables were compared by the $\chi^{2}$ test or Fisher's exact test using Statview version 5.0.

Data for the long-term outcomes were calculated using the Kaplan-Meier method and analyzed by the log-rank test. All $p$ values were two-sided, and $p$ values $\leq 0.05$ was considered to be statistically significant.

\section{Results}

En bloc resection rates, intra criteria resection rates and complication rates

Reported lesions treated are 1,136 gastric, 138 esophageal, and 361 colorectal. ESD experience was first gained in the stomach, next in colorectum, and then in the esophagus as the operator became more experienced. En bloc resection rates, intra criteria resection rates and complication rates are presented in Table 1.

Long-term follow-up

The follow-up for patients until June 2009 are presented in Table 2. The follow-up for lesions within guideline criteria and expanded criteria was a median of 53.4 (range, 0.07-98.6) months. Follow-up periods less than 23.6 months were caused by death from other cancers and unrelated diseases.

The organ-combined, 3 year overall survival rate for patients with lesions within guideline criteria was $93.4 \%$ and for expanded criteria $92.7 \%$. Five-year overall survival rate was $88.1 \%$ for guideline criteria lesions and $84.6 \%$ for expanded criteria lesions. The organ-specific survival is presented in Table 3. Survival curves overall and by organ 
Table 1 Patient and lesion demographic data, complication rates and resection rates

\begin{tabular}{|c|c|c|c|c|}
\hline & Stomach & Esophagus & Colorectum & Combined \\
\hline No. of lesions & 1136 & 138 & 361 & 1635 \\
\hline Age (years) & 71 & 69 & 68 & 70 \\
\hline [range] & [31-93] & [43-90] & [20-92] & {$[20-93]$} \\
\hline $\operatorname{Sex}(M: F)$ & $854: 282$ & $113: 25$ & $204: 157$ & 1171:464 \\
\hline Median tumor size $(\mathrm{cm})$ & 13 & 23 & 30 & 17 \\
\hline [range] & {$[1-105]$} & {$[1-72]$} & {$[6-158]$} & {$[1-158]$} \\
\hline Median resected specimen size $(\mathrm{cm})$ & 42 & 45 & 40 & 42 \\
\hline [range] & {$[14-153]$} & {$[22-90]$} & [16-165] & {$[14-165]$} \\
\hline \multicolumn{5}{|l|}{ Criteria $(\%)$} \\
\hline Guideline & $733(64.5)$ & $89(64.5)$ & $295(81.7)$ & $1117(68.3)$ \\
\hline Expanded & $235(20.7)$ & $25(18.1)$ & $29(8.0)$ & $289(17.7)$ \\
\hline Extra & $168(14.8)$ & $24(17.4)$ & $37(10.3)$ & $229(14.0)$ \\
\hline UL (+) & $\begin{array}{l}8.4 \% \\
(95 / 1136)\end{array}$ & - & - & \\
\hline$[95 \% \mathrm{CI}]$ & {$[6.8-10.0]$} & & & \\
\hline Postoperative bleeding & $\begin{array}{l}3.6 \% \\
(41 / 1136)\end{array}$ & $\begin{array}{l}0.0 \% \\
(0 / 138)\end{array}$ & $\begin{array}{l}1.7 \% \\
(6 / 361)\end{array}$ & $\begin{array}{l}2.9 \% \\
(47 / 1635)\end{array}$ \\
\hline$[95 \% \mathrm{CI}]$ & {$[2.5-4.7]$} & {$[0.0-0.0]$} & {$[0.4-3.0]$} & {$[2.1-3.7]$} \\
\hline Perforation & $\begin{array}{l}1.8 \% \\
(21 / 1136)\end{array}$ & $\begin{array}{l}0.0 \% \\
(0 / 138)\end{array}$ & $\begin{array}{l}1.9 \% \\
(7 / 361)\end{array}$ & $\begin{array}{l}1.7 \% \\
(28 / 1635)\end{array}$ \\
\hline En bloc resection & $\begin{array}{l}99.3 \% \\
(1128 / 1136)\end{array}$ & $\begin{array}{l}98.6 \% \\
(136 / 138)\end{array}$ & $\begin{array}{l}98.6 \% \\
(356 / 261)\end{array}$ & $\begin{array}{l}99.1 \% \\
(1620 / 1635)\end{array}$ \\
\hline$[95 \% \mathrm{CI}]$ & [98.8-99.8] & [96.6-100.6] & [97.4-99.8] & [98.6-99.6] \\
\hline En bloc R0 resection & $\begin{array}{l}97.1 \% \\
(1103 / 1136)\end{array}$ & $\begin{array}{l}95.7 \% \\
(132 / 138)\end{array}$ & $\begin{array}{l}98.3 \% \\
(355 / 361)\end{array}$ & $\begin{array}{l}97.2 \% \\
(1590 / 1635)\end{array}$ \\
\hline$[95 \% \mathrm{CI}]$ & {$[96.1-98.1]$} & [92.3-99.1] & [97.0-99.6] & [96.4-98.0] \\
\hline Intra criteria resection & $\begin{array}{l}84.9 \% \\
(964 / 1136)\end{array}$ & $\begin{array}{l}81.2 \% \\
(112 / 138)\end{array}$ & $\begin{array}{l}88.6 \% \\
(320 / 361)\end{array}$ & $\begin{array}{l}85.4 \% \\
(1396 / 1635)\end{array}$ \\
\hline$[95 \% \mathrm{CI}]$ & {$[82.8-87.0]$} & [74.7-87.7] & [85.3-91.9] & {$[83.7-87.1]$} \\
\hline
\end{tabular}

and lesions type (guideline criteria/expanded criteria/multiple lesions) are presented in Figs. 1, 2, 3, and 4. There was no significant difference in prognosis between guideline criteria and expanded criteria in stomach, esophagus, and colorectum, and there was no recurrence or disease-related death.

\section{Discussion}

Endoscopic submucosal dissection (ESD) has been widely accepted in Japan, because it has enabled the en bloc resection of early gastrointestinal neoplasms, and it is expected to be a curative but less radical treatment than conventional surgical treatment. This study represents the largest ESD cohort yet reported, leading to narrow confidence intervals for estimates, and the possibility to assess for differences in complications and en bloc resection rates between organs of the gastrointestinal tract to guide clinicians in assessing risks and benefits of ESD when appropriate for their patients. It also provides robust longterm follow-up data to guide likely prognosis following ESD for both organ- and lesion-specific indications.

Main findings

The en bloc $\mathrm{R} 0$ resection rate and intra criteria resection rate were similar and good in stomach, esophagus, and colorectum. Complication rates were low raging from 0 to $3.6 \%$. There were no complications (postoperative bleeding or perforation) in the esophagus; however, this may have been affected by prior experience in stomach and colorectum. Disease-specific survival rates following en bloc R0 resection were $100 \%$, probably reflecting the lack of recurrence noted. Long-term survival overall also was good, with no differences between organs.

Follow-up rate was high, in excess of $90 \%$, and followup period was a median of 4.4 years. There was no significant difference in prognosis between guideline criteria, 
Table 2 Patients follow-up rate to June 2009

\begin{tabular}{lcccccc}
\hline & $\begin{array}{l}\text { Guideline } \\
\text { criteria }\end{array}$ & $\begin{array}{l}\text { Expanded } \\
\text { criteria }\end{array}$ & $\begin{array}{l}\text { Multiple } \\
\text { lesions* }\end{array}$ & $\begin{array}{l}\text { Guideline criteria + Expanded } \\
\text { criteria + Multiple lesions* }\end{array}$ & $\begin{array}{l}\text { Total } \\
\text { patients }\end{array}$ & Follow-up rate \\
\hline Stomach & 387 & 132 & 153 & 672 & 701 & $95.9 \%(672 / 701)$ \\
Esophagus & 56 & 16 & 16 & 88 & 89 & $98.9 \%(88 / 89)$ \\
Colorectum & 226 & 25 & 18 & 269 & 295 & $91.2 \%(269 / 295)$ \\
Organ-combined & 669 & 173 & 187 & 1029 & 1085 & $94.8 \%(1,029 / 1085)$ \\
\hline
\end{tabular}

* Multiple lesions consisted of those in guideline criteria or expanded criteria

Table 3 3-Year and 5-year overall survival rates in organ-combined, stomach, esophagus, and colorectum

\begin{tabular}{|c|c|c|c|c|c|c|}
\hline & \multicolumn{3}{|c|}{ 3-Year overall survival (\%) } & \multicolumn{3}{|c|}{ 5-Year overall survival $(\%)$} \\
\hline & Guideline criteria & Expanded criteria & Multiple lesions & Guideline criteria & Expanded criteria & Multiple lesions \\
\hline Organ-combined & 93.4 & 92.7 & 92.4 & 89.6 & 83.5 & 85.3 \\
\hline Stomach & 91.7 & 92.2 & 92.8 & 88.1 & 84.6 & 85.9 \\
\hline Esophagus & 89.3 & 85.7 & 93.8 & 81.6 & 57.3 & 85.9 \\
\hline Colorectum & 97.3 & 100 & 87.5 & 94.3 & 100 & 78.7 \\
\hline
\end{tabular}

Fig. 1 Survival curves following ESD, split into guideline criteria, expanded criteria, and multiple lesions, organs combined

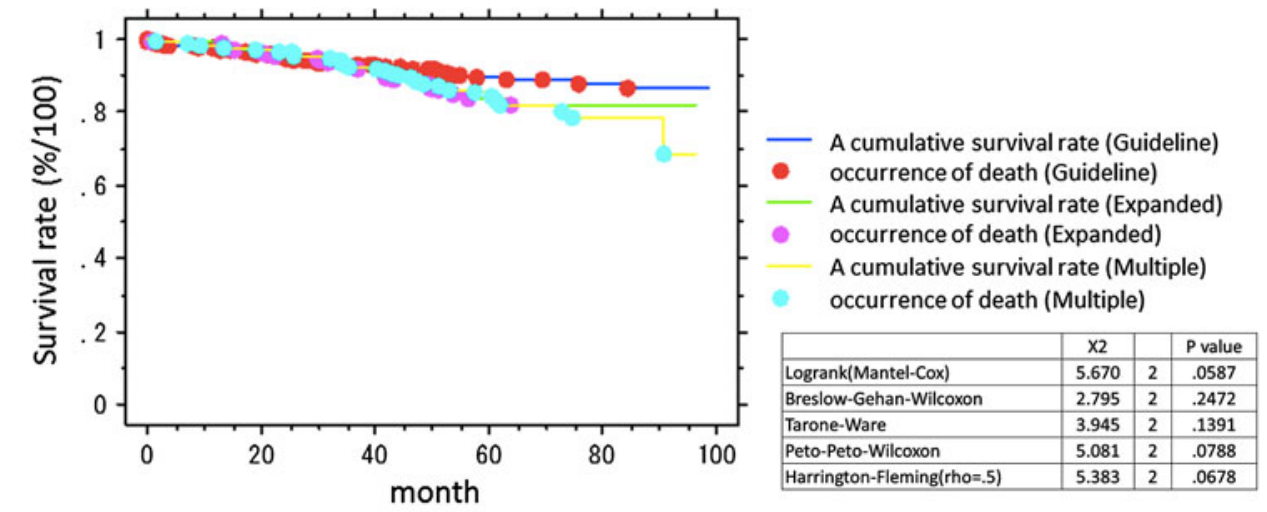

\begin{tabular}{|c|c|c|c|c|c|c|}
\hline & \multicolumn{3}{|c|}{3 year overall survival (\%) } & \multicolumn{3}{|c|}{5 year overall survival (\%) } \\
\hline & $\begin{array}{c}\text { Guideline } \\
\text { criteria }\end{array}$ & $\begin{array}{c}\text { Expanded } \\
\text { criteria }\end{array}$ & $\begin{array}{c}\text { Multiple } \\
\text { lesions }\end{array}$ & $\begin{array}{c}\text { Guideline } \\
\text { criteria }\end{array}$ & $\begin{array}{l}\text { Expanded } \\
\text { criteria }\end{array}$ & $\begin{array}{c}\text { Multiple } \\
\text { lesions }\end{array}$ \\
\hline Organ-combined & 93.4 & 92.7 & 92.4 & 89.6 & 83.5 & 85.3 \\
\hline
\end{tabular}

expanded criteria, and multiple lesions which consist of guideline or expanded criteria lesions. There was also no significant difference of prognosis in these three groups by organ or lesion criteria with no disease-specific death or recurrence, suggesting that the assumption that ESD is an appropriate and curative but less radical approach than surgery is true.

\section{Comparisons with other studies}

The overall and by organ en bloc resection rates are equal to or better than other series of ESD, where rates varied between 70 and $90 \%$ (stomach 76-96\%; esophagus
95-100 \%; colorectum 77-98.6 \%), and the perforation rates and perforation rates by organ also are similar to or lower than other series (bleeding rate/perforation rate: stomach 3-7\%/1-12\%; esophagus $0-1 \% / 6-7 \%$; colorectum $1-12 \% / 1-6 \%$ ) $[15,25-27]$.

A prospective, single-arm, multicenter, phase II trial for the prognosis of expanded criteria in stomach has started to address this, and the result will be available in 5 years [28]. Other prospective, multicenter studies looking at expanded criteria in the esophagus and colorectum are being planned. Pending those study outcomes, these results suggest that patients with lesions within guideline and expanded criteria treated by high-quality ESD are likely to have excellent long-term prognosis. 
Fig. 2 Survival curves following ESD, split into guideline criteria, expanded criteria, and multiple lesions, stomach

Fig. 3 Survival curves following ESD, split into guideline criteria, expanded criteria, and multiple lesions, esophagus

Fig. 4 Survival curves following ESD, split into guideline criteria, expanded criteria, and multiple lesions, colorectum

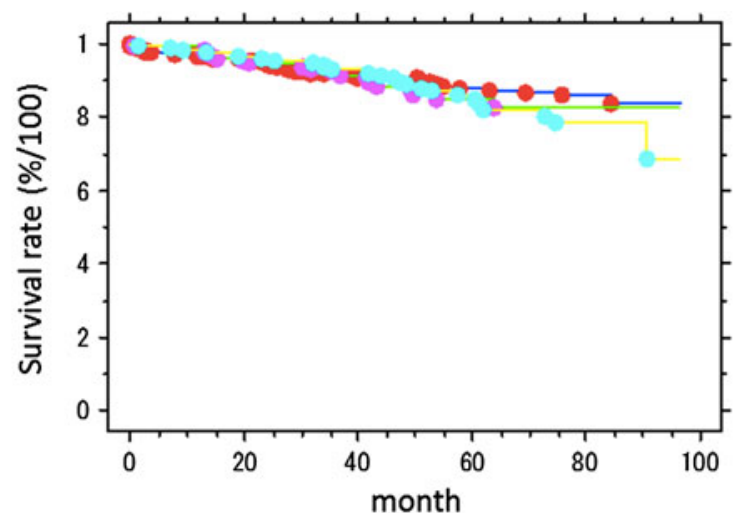

A cumulative survival rate (Guideline) occurrence of death (Guideline) A cumulative survival rate (Expanded) occurrence of death (Expanded) A cumulative survival rate (Multiple) occurrence of death (Multiple)

\begin{tabular}{|l|c|c|c|}
\hline & $\mathrm{X} 2$ & & P value \\
\hline Logrank(Mantel-Cox) & 1.490 & 2 & .4747 \\
\hline Breslow-Gehan-Wilcoxon & .478 & 2 & .7874 \\
\hline Tarone-Ware & .813 & 2 & .6658 \\
\hline Peto-Peto-Wilcoxon & 1.214 & 2 & .5449 \\
\hline Harrington-Fleming(rho=5) & 1.355 & 2 & .5080 \\
\hline
\end{tabular}

\begin{tabular}{|c|c|c|c|c|c|c|}
\hline & \multicolumn{3}{|c|}{3 year overall survival (\%) } & \multicolumn{3}{|c|}{5 year overall survival (\%) } \\
\hline & $\begin{array}{c}\text { Guideline } \\
\text { criteria }\end{array}$ & $\begin{array}{l}\text { Expanded } \\
\text { criteria }\end{array}$ & $\begin{array}{c}\text { Multiple } \\
\text { lesions }\end{array}$ & $\begin{array}{c}\text { Guideline } \\
\text { criteria }\end{array}$ & $\begin{array}{c}\text { Expanded } \\
\text { criteria }\end{array}$ & $\begin{array}{c}\text { Multiple } \\
\text { lesions }\end{array}$ \\
\hline Stomach & 91.7 & 92.2 & 92.8 & 88.1 & 84.9 & 85.9 \\
\hline
\end{tabular}

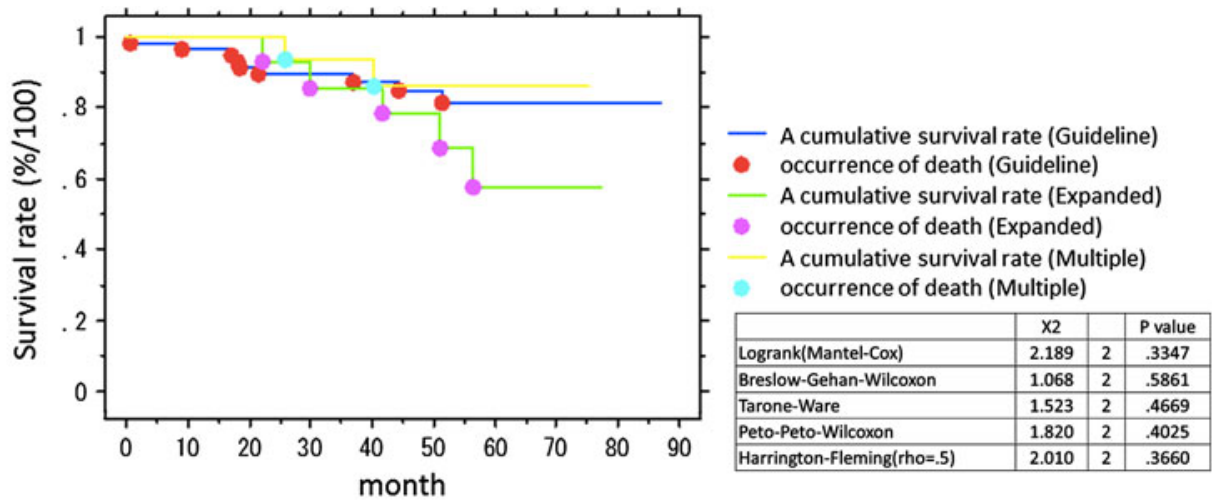

\begin{tabular}{|c|c|c|c|c|c|c|}
\hline & \multicolumn{3}{|c|}{3 year overall survival (\%) } & \multicolumn{3}{|c|}{5 year overall survival (\%) } \\
\hline & $\begin{array}{c}\text { Guideline } \\
\text { criteria }\end{array}$ & $\begin{array}{c}\text { Expanded } \\
\text { criteria }\end{array}$ & $\begin{array}{l}\text { Multiple } \\
\text { lesions }\end{array}$ & $\begin{array}{c}\text { Guideline } \\
\text { criteria }\end{array}$ & $\begin{array}{c}\text { Expanded } \\
\text { criteria }\end{array}$ & $\begin{array}{c}\text { Multiple } \\
\text { lesions }\end{array}$ \\
\hline Esophagus & 89.3 & 85.7 & 93.8 & 81.6 & 57.3 & 85.9 \\
\hline
\end{tabular}

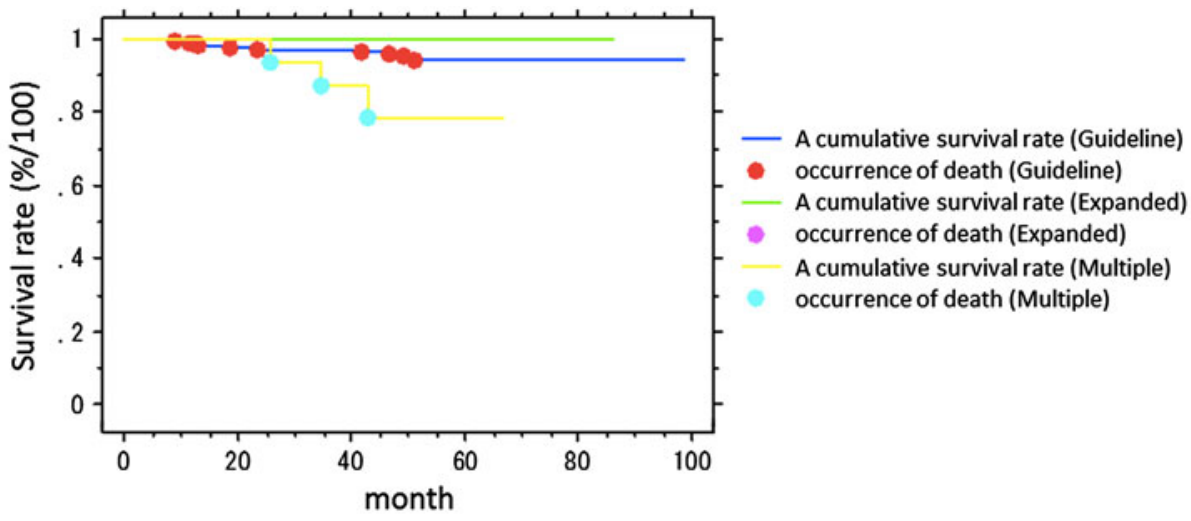

\begin{tabular}{|c|c|c|c|c|c|c|}
\hline & \multicolumn{3}{|c|}{3 year overall survival (\%) } & \multicolumn{3}{|c|}{5 year overall survival (\%) } \\
\hline & $\begin{array}{c}\text { Guideline } \\
\text { criteria }\end{array}$ & $\begin{array}{c}\text { Expanded } \\
\text { criteria }\end{array}$ & $\begin{array}{c}\text { Multiple } \\
\text { lesions }\end{array}$ & $\begin{array}{c}\text { Guideline } \\
\text { criteria }\end{array}$ & $\begin{array}{c}\text { Expanded } \\
\text { criteria }\end{array}$ & $\begin{array}{c}\text { Multiple } \\
\text { lesions }\end{array}$ \\
\hline Colorectum & 97.3 & 100 & 87.5 & 94.3 & 100 & 78.7 \\
\hline
\end{tabular}




\section{Clinical implications}

These data show that with careful technique and experience, ESD can be a safe procedure with low complication rates, high disease-specific cure rates, and good long-term survival. This should encourage clinicians to select ESD performed by experienced operators as a potential or even preferred treatment option for early gastrointestinal tract neoplasia. Paradoxically, although the esophagus is considered technically challenging due to thin wall and narrow lumen, in fact complications were lowest here.

\section{Limitations}

Most importantly, this was a single-operator, retrospective study, meaning that the results may not be generalizable; however, the majority of the data, such as lesion size and bleeding, was collected in a systematic way at the time the cases were performed, making the dataset relatively robust. Caution should be used in applying the data to non-Asian populations. The long-term survival rates may not be transferable to operators with lower en bloc R0 resection rates.

\section{Future directions}

ESD is evolving as a technique with little data from mature cohorts to assess its success. The current data support the use of ESD; however, the procedure remains technically demanding and time-consuming and complications continue to occur even after 1,000 procedures. More precise criteria on which lesions justify the risk and effort of ESD compared with EMR will be needed. Balanced against this is that development of endo-knives may make the procedure faster and safer, particularly the ability to inject fluid and cut within the same device. Improved hemostatic capacity via knife development, e.g., ball-tipped Flushknife [29], also may help. Fundamentally, if operators had endoscopes that would allow surgical type triangulation and tissue retraction, the procedure might become much faster and technically simpler. Such devices are being developed for NOTES procedures and may soon be available to support ESD.

\section{Conclusions}

In this large series performed by a single, experienced operator, ESD was associated with high curative resection rates and low complication rates in the short term across both upper and lower gastrointestinal tracts. Disease-specific and overall long-term prognoses were excellent after curative resection of criteria lesions. These data could help clinicians to choose ESD as curative but less radical treatment for the gastrointestinal tract, not only in guideline but also in expanded criteria.

Disclosures Dr. Toyonaga invented the Flushknife in conjunction with Fujifilm Inc., Tokyo, Japan, and receives royalties from its sale. M. Man-i, J. E. East, E. Nishino, W. Ono, T. Hirooka, C. Ueda, Y. Iwata, T. Sugiyama, T. Dozaiku, T. Hirooka, T. Fujita, H. Inokuchi, and T. Azuma have no conflicts of interest or financial ties to disclose.

Open Access This article is distributed under the terms of the Creative Commons Attribution License which permits any use, distribution, and reproduction in any medium, provided the original author(s) and the source are credited.

\section{References}

1. Soetikno RM, Kaltenbach T, Rouse RV, Park W, Maheshwari A, Sato T, Matsui S, Friedland S (2008) Prevalence of nonpolypoid (flat and depressed) colorectal neoplasms in asymptomatic and symptomatic adults. JAMA 299:1027-1035

2. Gotoda T, Kondo H, Ono H, Saito Y, Yamaguchi H, Saito D, Yokota T (1999) A new endoscopic mucosal resection procedure using an insulation-tipped electrosurgical knife for rectal flat lesions: report of two cases. Gastrointest Endosc 50:560-563

3. Ono H, Kondo H, Gotoda T, Shirao K, Yamaguchi H, Saito D, Hosokawa K, Shimoda T, Yoshida S (2001) Endoscopic mucosal resection for treatment of early gastric cancer. Gut 48:225-229

4. Oyama T, Kikuchi Y (2002) Aggressive endoscopic mucosal dissection in the upper GI tract: hook knife EMR method. Minim Invasive Ther Allied Technol 11:291-295

5. Yahagi N, Fujishiro M, Kakushima N, Kobayashi K, Hashimoto T, Oka M, Iguchi M, Enomoto S, Ichinose M, Niwa H, Omata M (2004) Endoscopic submucosal dissection for early gastric cancer using the tip of an electro surgical snare (thin type). Dig Endosc 16:34-38

6. Rosch T, Sarbia M, Schumacher B, Deinert K, Frimberger E, Toermer T, Stolte M, Neuhaus H (2004) Attempted endoscopic en bloc resection of mucosal and submucosal tumors using insulated-tip knives: a pilot series. Endoscopy 36:788-801

7. Neuhaus H, Costamagna G, Deviere J, Fockens P, Ponchon T, Rösch T, ARCADE Group (2006) Endoscopic submucosal dissection of early gastric lesions using a new double channel endoscope (the "R-scope"). Endoscopy 38:1016-1023

8. Kodashima S, Fujishiro M, Yahagi N, Kakushima N, Omata M (2006) Endoscopic submucosal dissection using Flex knife. J Clin Gastroenterol 40:378-384

9. Yamamoto H, Yahagi N, Oyama T (2005) Mucosectomy in the colon with endoscopic submucosal dissection. Endoscopy 37:764-768

10. The Paris endoscopic classification of superficial neoplastic lesions: esophagus, stomach, and colon: November 30 to December 1, 2002 (2003) Gastrointest Endosc 58:S3-43

11. Kitajima K, Fujimori T, Fujii S, Takeda J, Ohkura Y, Kawamata H, Kumamoto T, Ishiguro S, Kato Y, Shimoda T, Iwashita A, Ajioka Y, Watanabe H, Watanabe T, Muto T, Nagasako K (2004) Correlations between lymph node metastasis and depth of submucosal invasion in submucosal invasive colorectal carcinoma: a Japanese collaborative study. J Gastroenterol 39:534-543

12. Japanese Gastric Cancer Association (2004) Guidelines for diagnosis and treatment of carcinoma of the stomach

13. Gotoda T, Yanagisawa A, Sasako M, Ono H, Nakanishi Y, Shimoda T, Kato Y (2000) Incidence of lymph node metastasis 
from early gastric cancer: estimation with a large number of cases at two large centers. Gastric Cancer 3:219-225

14. Kodama M, Kakegawa T (1998) Treatment of superficial cancer of the esophagus: a summary of responses to a questionnaire on superficial cancer of the esophagus in Japan. Surgery 123: 432-439

15. Oyama T, Tomori A, Hotta K, Morita S, Kominato K, Tanaka M, Miyata Y (2005) Endoscopic submucosal dissection of early esophageal cancer. Clin Gastroenterol Hepatol 3(7 Suppl 1): S67-70

16. Ueno H, Mochizuki H, Hashiguchi Y, Shimazaki H, Aida S, Hase K, Matsukuma S, Kanai T, Kurihara H, Ozawa K, Yoshimura K, Bekku S (2004) Risk factors for an adverse outcome in early invasive colorectal carcinoma. Gastroenterology 127:385-394

17. Toyonaga T, Nishino E, Hirooka T, Hayashibe A (2005) Invention of water jet short needle knives for endoscopic submucosal dissection. Endoscopy 37:A19

18. Toyonaga $\mathrm{T}$, Inokuchi $\mathrm{H}$, Man-I M, Morita $\mathrm{Y}$, Yoshida M, Kutsumi H, Azuma T (2007) Endoscopic submucosal dissection using water jet short needle knives (Flush knife) for the treatment of gastrointestinal epithelial neoplasms. Acta Endoscopica 37: 645-656

19. Yamamoto H, Yube T, Isoda N, Sato Y, Sekine Y, Higashizawa T, Ido K, Kimura K, Kanai N (1999) A novel method of endoscopic mucosal resection using sodium hyaluronate. Gastrointest Endosc 50:251-256

20. Toyonaga T, Nishino E, Hirooka T, Dozaiku T, Sugiyama T, Iwata Y, Ono W, Ueda C, Tomita M, Hirooka T, Makimoto S, Hayashibe A, Sonomura T (2005) Use of short needle knife for esophageal endoscopic submucosal dissection. Dig Endosc 17: 246-252

21. Toyonaga T, Nishino E, Hirooka T, Ueda C, Noda K (2006) Intraoperative bleeding in endoscopic submucosal dissection in the stomach and strategy for prevention and treatment. Dig Endosc 18:S123-S127
22. Toyonaga T, Man-i M, Fujita T, East JE, Nishino E, Ono W, Morita Y, Sanuki T, Yoshida M, Kutsumi H, Inokuchi H, Azuma T (2010) Retrospective study of technical aspects and complications of endoscopic submucosal dissection for laterally spreading tumors of the colorectum. Endoscopy 42:714-722

23. Toyonaga T (2006) ESD atlas [in Japanese]. Kanehara Shuppan, Tokyo

24. von Elm E, Altman DG, Egger M, Pocock SJ, Gøtzsche PC, Vandenbroucke JP, STROBE Initiative (2007) The strengthening the reporting of observational studies in epidemiology (STROBE) statement: guidelines for reporting observational studies. Ann Intern Med 147:573-577

25. Kakushima N, Fujishiro M (2008) Endoscopic submucosal dissection for gastrointestinal neoplasms. World J Gastroenterol 14:2962-2967

26. Oda I, Gotoda T, Hamanaka H, Eguchi T, Saito Y, Matsuda T, Bhandari P, Emura F, Saito D, Ono H (2005) Endoscopic submucosal dissection for early gastric cancer: technical feasibility, operation time and complications from a large consecutive series. Dig Endosc 17:54-58

27. Saito Y, Uraoka T, Matsuda T, Emura F, Ikehara H, Mashimo Y, Kikuchi T, Fu KI, Sano Y, Saito D (2007) Endoscopic treatment of large superficial colorectal tumors: a case series of 200 endoscopic submucosal dissections (with video). Gastrointest Endosc 66:966-973

28. Kurokawa Y, Hasuike N, Ono H, Boku N, Fukuda H, Gastrointestinal Oncology Study Group of Japan Clinical Oncology Group (2009). A phase II trial of endoscopic submucosal dissection for mucosal gastric cancer: Japan Clinical Oncology Group Study JCOG0607. Jpn J Clin Oncol 39:464-466

29. Toyonaga T, Man-i M, Fujita T, Nishino E, Ono W, Morita Y, Sanuki T, Masuda A, Yoshida M, Kutsumi H, Inokuchi $\mathrm{H}$, Azuma T (2010) The performance of a novel ball-tipped Flush knife for endoscopic submucosal dissection: a case-control study. Aliment Pharmacol Ther 32:908-915 